\title{
THE RATE OF FERMENTATION OF CIDERS AND PERRIES.
}

\author{
BY \\ B. T. P. BARKER, M.A., \\ National Fruit and Cider Institute.
}

THE most striking feature of the fermentation of ciders and perries is the great variation in the rate of fermentation which is met with. It is the regular experience of cider makers that casks of cider, standing side by side in the same cellar, made at the same time, and treated throughout in similar fashion, ferment in nearly every instance with different degrees of rapidity. For example, the specific gravity in one cask may fall from 1.050 to 1.046 in the course of three or four weeks, while in its neighbour the drop may be from 1.050 to 1.000 . Variations of this kind make it difficult to exercise much control over the nature of the product, and absolute uniformity in the character of the mature ciders cannot be expected. In point of fact uniformity in every case is not desired, since ciders of various grades of sweetness and dryness are required for market purposes. In other words, ciders with specific gravities ranging from 1.000 to 1.040 or even higher, all find a place on the market. It is not satisfactory, however, that the production of a cider of any particular type should be left mainly to chance, as is generally the case: and to obtain control, the power of producing at will a cider of low or of high specific gravity is essential, and involves a knowledge of the factors which determine and govern the rate of fermentation. The work described in this paper was undertaken with the object of gaining some idea of the nature and influence of these factors, and of ascertaining how they could be utilised to practical advautage. It was carried out at the National Fruit and Cider Institute, where the ciders investigated were made, in some cases on a practical scale in the cider house, and in the remainder on a more limited scale in the laboratory. 


\title{
2 The Rate of Fermentation of Ciders and Perries
}

\author{
The relation between the variety of apple used and the \\ rate of fermentation.
}

The Tables A and B (pp. 4, 5, 6) give records of the drop in specific gravity of ciders and perries investigated during the seasons 1904-05, 05-06, and 06-07. They were made in each case in the cider house, and were kept during the course of fermentation in the cellar, at the ordinary cellar temperature, which, although varying according to the outdoor temperature, usually ranged between $45^{\circ}$ and $50^{\circ} \mathrm{F}$. The total bulk of the juice was usually about 54 gallons, but in certain cases the quantity was as small as 19 gallons, and in others as much as 120 gallons. Each cider or perry was made from one kind of apple or pear only, the fruit being milled when it was judged to be in fit condition. The general treatment was the same in all cases referred to in Table A, the juice after its expression from the pulped fruit being "keeved" and afterwards pumped into the fermenting cask, which was filled to the bung-hole, and allowed to remain there undisturbed until the time of filtration. The weekly records are not extended beyond that point, since the process of filtration causes a radical alteration in the normal course of fermentation. The records were for the most part taken at regular weekly intervals, but in those cases where the interval was longer, the total drop during such periods has been averaged so as to show approximately the weekly fall for the intervening time.

Table A gives the weekly records of gravities taken direct from the liquor in cask. Table B gives the daily records of gravities of the ciders kept at $25^{\circ} \mathrm{C}$. In these cases sample bottles of the fresh juices were taken from each cask as sonn as filled, and the gravities given are those of the liquids in these bottles, the same ciders in bulk being kept in casks in the cellar at the ordinary temperature. There was very little difference between the comparative rates of fermentation of the different ciders in bottle at $25^{\circ} \mathrm{C}$, and in cask at the ordinary temperature.

It will be seen from these tables that there are wide variations in the rate of fermentation of the ciders made from different varieties of apples: and that in some cases extreme variations occur in the ciders made from the same variety. As an instance of this, the two Strawberry Norman ciders made in 1904-5 may be referred to. But while it is not uncommon to find such variations in the case of any particular variety, on the whole it may be claimed that there is some relation between the rate of fermentation of the cider and the variety 
of apple from which the cider is made. The Kingston Black ciders and Oldfield perries in each season, referred to in the tables, fermented at a moderately slow rate. The Sweet Alford, Cap of Liberty, and Frederick, among others, also regularly fermented more slowly than the average cider. No good examples of ciders with consistently rapid fermentation can be quoted from the above tables with the exception of Northwood, since such varieties are noted for the poor quality of the product, and were therefore not procured in quantity for experimental purposes in successive seasons. However, in several cases small lots of the fruit were tested in the laboratory, and the results in those experiments proved that the rate of fermentation is normally rapid for many varieties. Such kinds are Morgan Sweet, Fair Maid of Devon, Tom Putt, and Broadleaf, which also on the single occasion tested in the cider house and referred to in the tables (pp. 4, 5, 6), gave similar results. The experience of practical cider makers confirms the results obtained for the varieties mentioned as yielding slowly or rapidly fermenting ciders.

Although a certain amount of agreement in the results for these varieties has been noted, which is sufficient perhaps to justify the statement that there is a relation between the variety of apple or pear and the rate of fermentation of the juice, it is highly probable that this relation is much closer than appears from the statistics given. There are other factors which have a material influence upon the rate of fermentation, and they undoubtedly tend to obscure the "variety" influence. They are considered in detail below; and among those likely to be largely accountable for the different behaviour of ciders made from the same variety of apple may be mentioned the condition of ripeness of the fruit at the time of milling, the extent to which it has been exposed to the sun, and the kind of soil upon which it was grown.

\section{The causes of the variations in the rate of fermentation.}

While it has thus been shown that there is to a certain extent some connexion between the rate of fermentation and the variety of apple or pear from which the cider or perry is made, the more immediate causes of the variations remain to be considered. The various factors which were investigated include the chemical composition of the juice, the state of ripeness of the fruit at the time of making, the organisms taking part in the fermentation, the temperature at which the fermentation was conducted, and the aeration of the cider. The nature of the 
4 The Rate of Fermentation of Ciders and Perries

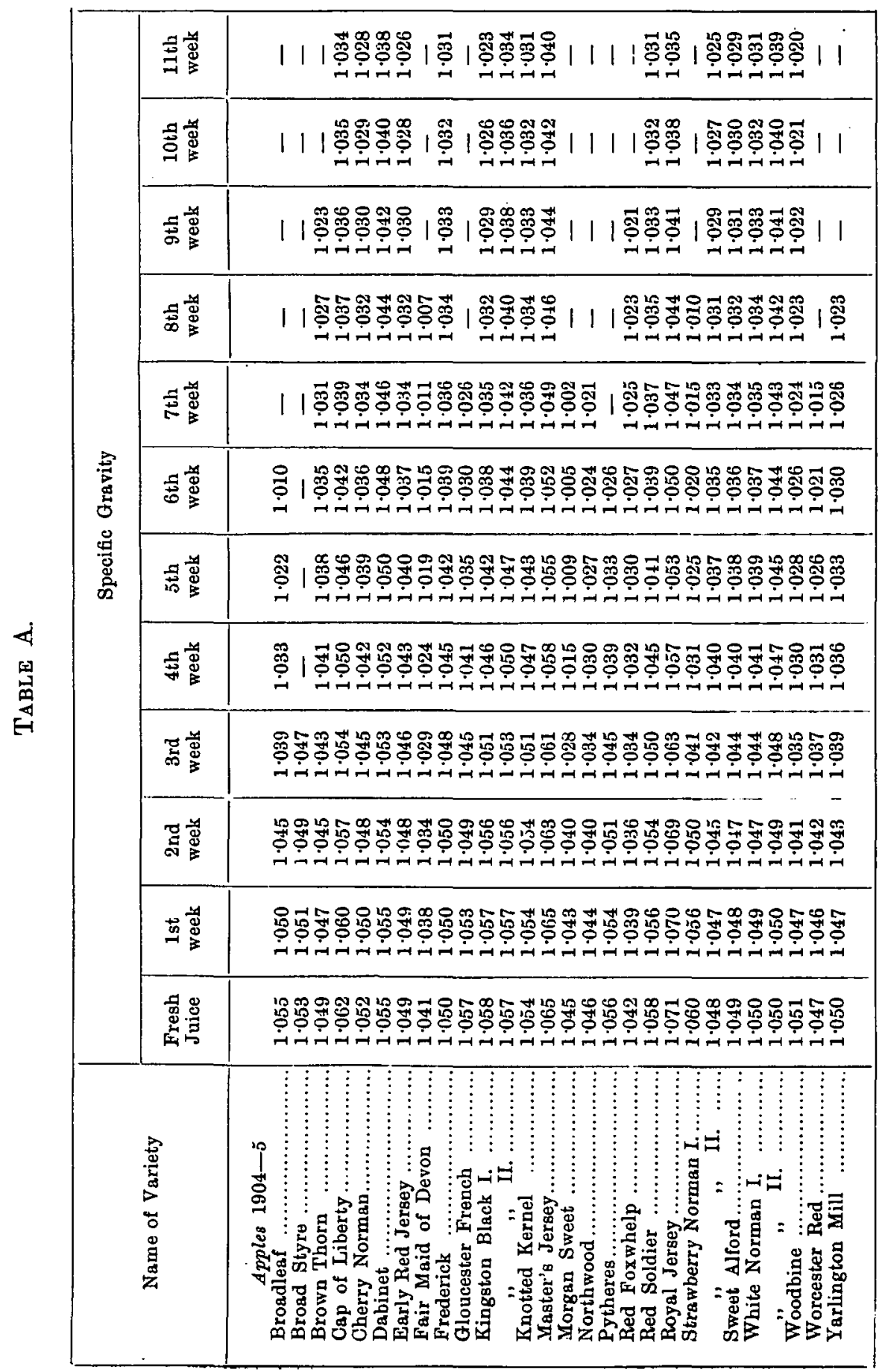


B. T. P. BARKER

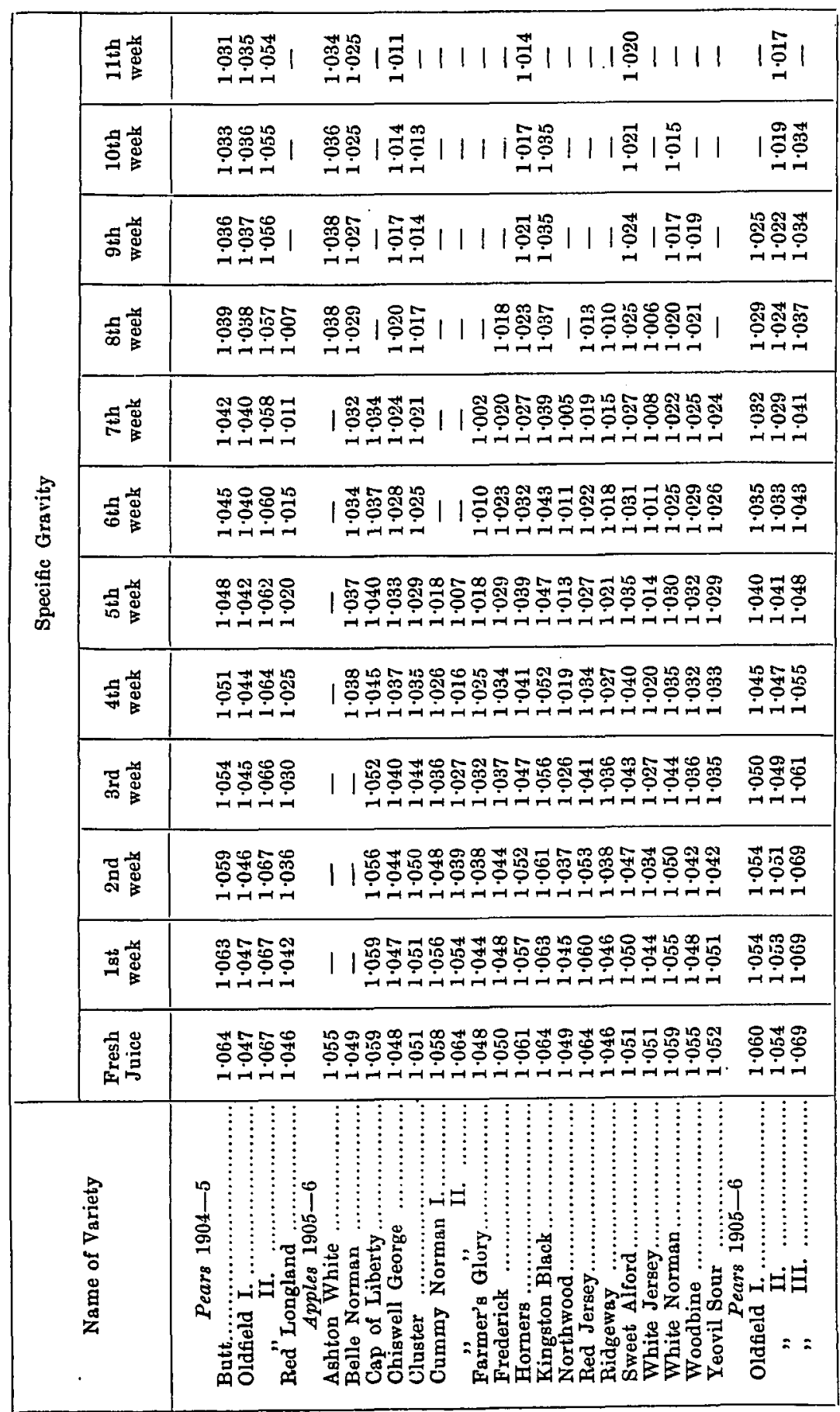


6 The Rate of Fermentation of Ciders and Perries

\begin{tabular}{|c|c|c|}
\hline \multirow{12}{*}{ 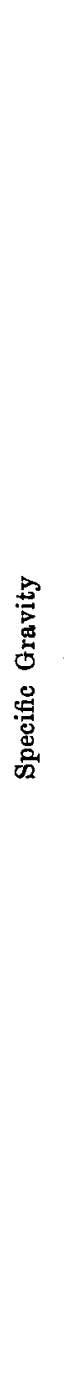 } & 券兽 & 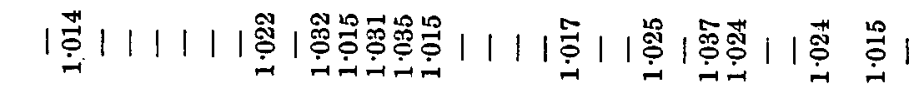 \\
\hline & 言密 & 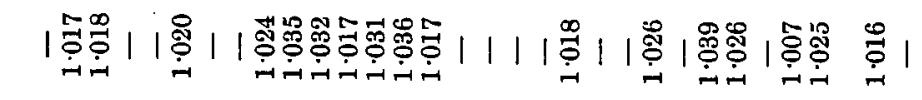 \\
\hline & 票密 & | \\
\hline & 超急 & 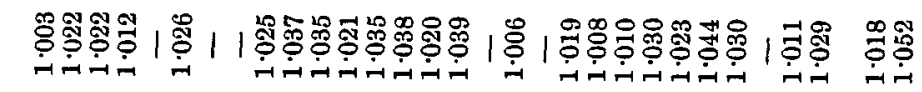 \\
\hline & 吾票 & 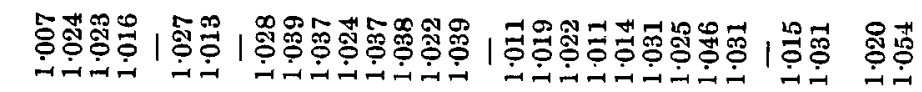 \\
\hline & 홍영 & 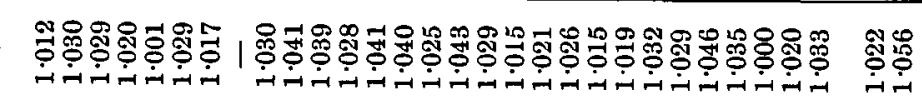 \\
\hline & 者窘 & 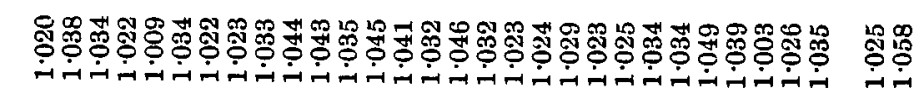 \\
\hline & 孚密 & 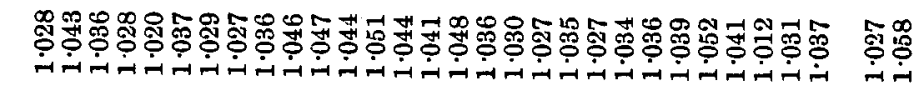 \\
\hline & $\overrightarrow{\mathbb{\aleph}^{\circ}}$ & 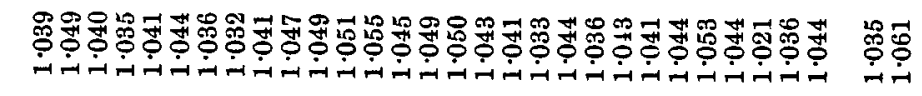 \\
\hline & 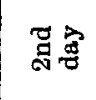 & 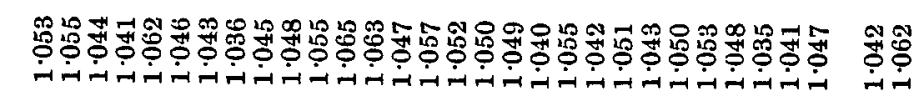 \\
\hline & 㟒 & 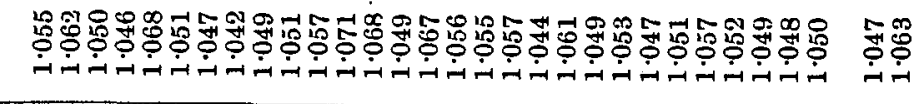 \\
\hline & 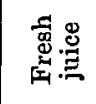 & 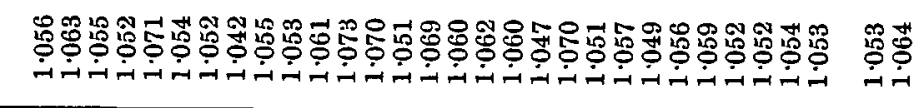 \\
\hline & 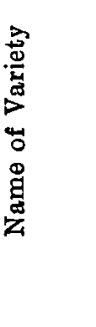 & 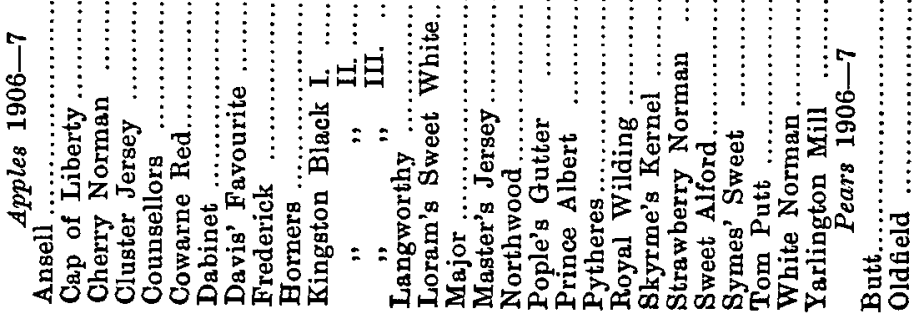 \\
\hline
\end{tabular}


soil upon which the fruit is grown may have an important influence: and it is commonly asserted by practical cider makers that they have proved it to be the case. The soil factor, however, must be left for future consideration, since definite conclusions based on the limited data at present available are not justified.

\section{The influence of the chemical composition of the juice.}

The chemical composition of the juice obtained from the different kinds of apples varies considerably. Analyses of French and German cider apples have been published by Truelle (7) and Kulisch (5) among others. Allwood (1) has given details of the composition of the juice of several American varieties, while Hogg and Graves Bull (4), Lloyd (6) and myself (2) have published analyses of a very large number of English vintage varieties. They may be grouped into three main classes, "sours," "sweets," and "bittersweets," according to the composition of their juice. The "sours" include those with juices containing normally 45 per cent. malic acid and upwards; the "sweets" those with juices containing normally less than 45 per cent. malic acid and $\cdot 20$ per cent. tannin; and the "bittersweets" those with juices containing normally less than 45 per cent. malic acid and more than 20 per cent. tannin. The percentage of sugar in the juice varies widely, even for the same variety. For vintage purposes the usual contents of the juice which are considered of primary importance are sugar, tannin and malic acid. The percentages of the other substances present in the juice, including mucilages, nitrogenous substances, and ash constituents, are very small and comparatively little attention has been paid to them.

The analyses of the ciders dealt with in Table $\mathbf{A}$ have been given elsewhere (2). A detailed comparison of the composition of the various fresh juices as regards total solid matter, sugar, tannin, malic acid, and total extractives, with their rates of fermentation, fails to show any signs of a direct relation between the quantity present of any one of those substances and the rate of fermentation. For example, Counsellor cider with an original gravity of 1.071 showed a drop to 1.001 in 6 days at $25^{\circ} \mathrm{C}$., while Kingston Black cider with an original gravity of 1.070 only dropped to 1.045 in the same period. Again, Strawberry Norman cider containing 650 per cent. of tannin showed a drop in specitic gravity from 1.060 to 1.010 while Royal Jersey cider containing 700 per cent. tannin in the same period only dropped from 1.071 to 1.044. Also, Fair Maid of Devon cider containing 75 per cent. malic acid 


\section{The Rate of Fermentation of Ciders and Perries}

showed a fall from 1.041 to 1.007, while Cap of Liberty cider containing 1.01 per cent. malic acid suffered in the same period a drop from 1.062 to 1.037 only. At the same time the amounts of these substances in some cases, especially in the case of tannin, may have some influence, although it is certainly overwhelmed and obscured by that of other factors.

Since the observed differences in the rate of fermentation of the juices of different varieties of apples and pears are not due to any of the substances just mentioned, it follows that either the chemical composition has little influence or else the effect is brought about by one or more of the substances which are present in very limited quantities and are not determined in the usual analyses. There were certain reasons for believing that the latter alternative was the correct one, since, as will be pointed out later, the kinds of yeast present did not appear to be responsible for the differences, and the nutrition of the yeasts seemed defective. It was previously known, too, that the fermentation of many fruit juices is slow and irregular owing to the lack of assimilable nitrogenous substances, required for satisfactory yeast nutrition. It seemed desirable, therefore, to ascertain if, in the slowly fermenting apple and pear juices, any of the elements necessary for the proper nutrition of the yeasts were absent or, if present, occurred in quantities too small to meet the full demands of the yeasts. The subject was not attacked by direct estimation of the essential elements, partly because the quantity required in some cases is so small, and partly because of the difficulty of determining if any particular element occurred in a form readily assimilable by the yeast. The test method adopted was to add to the cider small quantities of each of the respective elements required in forms known to be assimilable by the yeast, and to watch the effect on the rate of fermentation. Several different ciders were tested in this way, and in every case the rate of fermentation was only affected when assimilable nitrogenous substances were added. None of the other elements requisite for yeast nutrition had any appreciable effect in the fermentation. Tables $\mathrm{C}$ and $\mathrm{D}$ (p. 9) give the results obtained for Oldfield perry and White Norman cider. The following method was employed:

200 c.c. of the juice in an Erlenmeyer flask was used in each case, and the cider was left undisturbed at $25^{\circ} \mathrm{C}$. during the course of the experiments. The experiments were started in February 1905, the juices thus being about three months old at the time, during which 
time they had been subjected to fermentation in the ordinary manner in bulk in the cider house, the samples being taken direct from the casks for the purpose of these tests. The addition of one per cent. ammonium tartrate caused a rise in specific gravity of 5 points, and of 5 per cent. potassium phosphate and magnesium sulphate respectively, 2 points; so that actually the specific gravities of the Oldfield $b, c, d$ and $e$ were $1.058,1.054,1.051$ and 1.051 respectively at the start of the experiment as compared with 1.049 for the untreated juice $a$, and of the White Norman $b, c, d$ and $e$ 1.045, 1.041, 1.038 and 1.038 respectively as compared with 1.036 for $a$. In all cases a certain amount of acetification occurred, but there was less in $b$ and $c$ of both series-the only ciders which fermented at all actively - than in the others.

\section{Table C. Oldfield Perry.}

Specific gravity of untreated juice at the beginning of the experiment $1 \cdot 049$.

\begin{tabular}{|c|c|c|c|c|}
\hline ", & ", & after 20 & C. & a $1.04 \tilde{j}$ \\
\hline$"$ & $"$ & $"$ & ", & $b 1 \cdot 014$ \\
\hline ", & $"$ & $"$ & $"$ & c 1.006 \\
\hline , & " & $"$ & $"$ & $a 1 \cdot 048$ \\
\hline ," & ", & " & $"$ & e 1.051 \\
\hline ", & , & $"$ & $"$ & $f 1.049$ \\
\hline$"$ & $"$ & $"$ & $"$ & $g 1.047$ \\
\hline
\end{tabular}

TABLE D. White Norman Cider.

Specific gravity of untreated juice at the beginning of the experiment 1.036 .

\begin{tabular}{|c|c|c|c|c|}
\hline$"$ & $"$ & after 14 & C. & $a 1.03$ \\
\hline , & $"$ & $"$ & $"$ & $b 1.011$ \\
\hline "' & $"$ & " & $"$ & c 1.011 \\
\hline " & " & " & ", & $d 1 \cdot 032$ \\
\hline$"$ & $"$ & $"$ & $"$ & c 1.032 \\
\hline ? & $"$ & $"$ & $"$ & $f 1.030$ \\
\hline
\end{tabular}

In both series $a$ was the juice without any addition

$b$ was juice to which was added 1 per cent. ammonium tartrate

$.5 \quad, \quad$ potassium phosphate
$.5 \quad " \quad$ magnesium sulphate
$.05 \quad " \quad$ calcium phosphate
and a trace of ferric chloride
1 per cent. ammonium tartrate only
$.5 \quad$ " potassium phosphate only
$.5 \quad$ magnesium sulphate only
$.05 \quad "$ calcium phosphate only
a trace of ferric chloride only.

The results show clearly that the addition of assimilable nitrogenous substances to slowly fermenting ciders is required to produce an 


\section{The Rate of Fermentation of Ciders and Perries}

increase in the rate of fermentation. Indeed, their addition to any juice usually results in an increased rate. Consequently it must be concluded that apple and pear juices are naturally more or less deficient in those substances, and that the rate of fermentation depends on the quantity, and possibly the nature, of those present, other conditions being equal.

Ammonium tartrate was used in these experiments as the source of nitrogen for yeast assimilation, but in other cases the effects of peptone and asparagin were also tested. As with ammonium tartrate, the rate of fermentation was increased by their addition, but the increase was as a rule not so pronounced as with the former substance.

That the addition of assimilable nitrogenous material causes an increase in the rate of fermentation in fresh juices as well as in the older liquors was proved by the following example.

TABLE E.

\begin{tabular}{|c|c|c|c|c|c|}
\hline \multirow{2}{*}{$\begin{array}{c}\text { Juice from mixed apples } \\
\text { kept at } 25^{\circ} \mathrm{C} .\end{array}$} & \multicolumn{5}{|c|}{ Specific gravity } \\
\cline { 2 - 6 } & $\begin{array}{c}\text { at beginning } \\
\text { of experiment }\end{array}$ & $\begin{array}{c}\text { at the end } \\
\text { of } 24 \mathrm{hrs}\end{array}$ & $\begin{array}{c}\text { do. } \\
48 \mathrm{hrs} .\end{array}$ & $\begin{array}{c}\text { do. } \\
72 \mathrm{hrs} .\end{array}$ & $\begin{array}{c}\text { do. } \\
96 \mathrm{hrs} .\end{array}$ \\
\hline $\begin{array}{c}\text { Juice alone............... } \\
\text { Juice }+1 \% \% \text { asparagin ... }\end{array}$ & $\begin{array}{c}1.038 \\
1.038\end{array}$ & $\begin{array}{c}1.036 \\
1.032\end{array}$ & $\begin{array}{c}1.029 \\
1.018\end{array}$ & $\begin{array}{c}1.021 \\
1.004\end{array}$ & $\begin{array}{c}1.016 \\
1.001\end{array}$ \\
\hline
\end{tabular}

The effect of the addition of assimilable nitrogenous substances is so pronounced, that this factor of the quantity of such substances naturally present in the juice is quite sufficient in itself to account fully for the differences in the rate of fermentation of any ciders, made and fermented under similar conditions.

The chemical composition of apple and pear juice varies considerably according to the state of ripeness of the fruit from which the juice was obtained. The variation is naturally most marked in the cases of the contents of sugar and of the specific gravity, but the amounts of malic acid, tannin and many of the other constituents occurring in smaller quantity are also affected. It would be expected therefore that the rate of fermentation might be likewise affected. This was proved to be the case by comparing the records of the rate of fermentation of the juices obtained from fruit grown on the same tree but pressed at different stages of ripeness. A large quantity of Early Red Jersey 
apples was gathered on the same day from one of the trees of this variety in the orchard at the Institute, before they were fully ripe. They were sorted into three lots, one lot composed entirely of green unripe specimens, another of well-coloured fruit more or less ripe and the third of fruit showing the first signs of decay due to over-ripeness. The juice was expressed from samples taken from each lot at weekly intervals and the rate of fermentation at the ordinary laboratory temperature (about $60^{\circ} \mathrm{F}$.) noted in each case. The quantity of juice used in each instance was 10 ozs.; and this was kept in 10 oz. bottles, so that each bottle was filled to the neck and any possible influence due to the action of air on the juice thus rendered the same for all. Table $\mathrm{F}$ contains the records of the specific gravities taken after various intervals. The date on which the first specific gravity in each case is recorded is the date of pressing.

TABLE F.

\begin{tabular}{|c|c|c|c|c|c|c|c|c|c|}
\hline \multirow{2}{*}{$\begin{array}{c}\text { Juice obtained } \\
\text { from early Red } \\
\text { Jersey apples }\end{array}$} & \multicolumn{9}{|c|}{ Specific gravity } \\
\hline & Sept. 29 & Oct. 6 & Oet. 14 & Oct. 21 & Nor. 7 & Nov. 21 & Dec. 22, & Jau, 12 & Jan. 29 \\
\hline A $1 \mathrm{u}$ & 1.047 & 1.045 & 1.035 & 1.026 & $1 \cdot 012$ & 1.006 & .998 & - & - \\
\hline & & $1 \cdot 0$ & & 1.040 & & & 1.020 & $1 \cdot \overline{019}$ & 1.019 \\
\hline B & $\cdots$ & 1.050 & & $\begin{array}{l}1.040 \\
0\end{array}$ & & & .998 & 101 & \\
\hline B 2 ripe...... & $=$ & 1.052 & 1.051 & $\begin{array}{l}1.050 \\
1.050\end{array}$ & 1.0 & $\begin{array}{l}1.042 \\
1.04\end{array}$ & $\begin{array}{l}1.032 \\
\end{array}$ & $1 \cdot \overline{031}$ & $1 \cdot \overline{029}$ \\
\hline $\mathrm{C} 1 \mathrm{u}$ & - & - & 1.0505 & 1.048 & & 1.0 & $1 \cdot$ & - & .999 \\
\hline 02 & - & - & $1 \cdot 0$ & & & & & $1 \cdot 037$ & 1.035 \\
\hline C 30 & ב & - & $1 \cdot 045$ & 1.0 & 1.0 & 1.0 & 1.035 & 1.033 & 1.031 \\
\hline D $1 \mathrm{u}$ & . & _ & $\ldots$ & 1.052 & 1. & 1.0 & 1.006 & 100 & $\begin{array}{r}.908 \\
.998\end{array}$ \\
\hline & - & 二 & 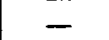 & $\begin{array}{l}1.055 \\
1.055\end{array}$ & & 1.049 & & $1 \cdot 032$ & 1.025 \\
\hline D 3 ov & - & 二 & 二 & $\begin{array}{l}1.056 \\
1.00\end{array}$ & 1.055 & 1.046 & 1.029 & 1.023 & 1.018 \\
\hline E 1 nnr & Z & - & - & - & 1.0 & $1 \cdot 0$ & 1.000 & & - \\
\hline $\mathrm{E} 2 \mathrm{ri}$ & - & -- & - & - & 1.0 & 1.050 & 1.034 & 1.026 & $1 \cdot 018$ \\
\hline E 3 over-ripe & & - & - & - & 1.055 & 1.053 & 1.009 & 1.002 & $1 \cdot 001$ \\
\hline
\end{tabular}

From this table it will be seen that in every case the juice obtained from uuripe fruit fermented rapidly to dryness, and that there was no great difference in the rate in either instance. The slowest rate was in $\mathrm{C} 1$; and it is significant that the slowest rates for the ripe and overripe juices occurred in $\mathrm{C} 2$ and $\mathrm{C} 3$, which were made on the same day as $\mathrm{C} 1$. The ciders obtained from the ripe samples of fruit showed very interesting variations in the rate. Thus B 2 fermented more slowly than A 2, and C 2 rather more slowly than B 2: then the rate gradually increases in the later samples, the rate in $\mathrm{D} 2$ being more 


\section{The Rate of Fermentation of Ciders and Perries}

rapid than in $\mathrm{C} 2$, and in $\mathrm{E} 2$ than in $\mathrm{D} 2$. In the latter respect the over-ripe samples C 3, D 3 and E 3 also agree. C 3 was the first of the over-ripe samples made, since before that time there was not sufficient distinction between that fruit and the fruit used for the "ripe" samples to justify any separation. Therefore the statistics for A 2 and B 2 may fairly stand for the over-ripe class also, in which case it will be noticed that there is a similar gradual decrease, and then an increase, in the comparative rates of fermentation of the samples made up in successive weeks for the over-ripe as well as for the ripe fruit. The same may be said for the unripe fruit; but on account of the fermentation being much more rapid the variation is not so well marked.

The terms "unripe," "ripe" and "over-ripe," as used above, need qualification. They are used in a comparative sense only, since obviously the absolute condition of ripeness varied from week to week. Thus the "ripe" specimens, for example, were in reality only properly and fully ripe between about October 4th and October 16th. Each set of fruit therefore during the course of the experiment actually passed through stages of comparative unripeness to full maturity and onwards to over-ripeness.

Allowing for this, it is clear therefore from the above statistics that, during the course of ripening of an apple, changes of chemical composition occur in the juice, which cause a gradual reduction in the potential rate of fermentation, until the apple attains full ripeness, after which point, as maturity merges into decay, the rate gradually increases.

An interesting point arising out of the preceding experiment, is the relation between the extent of development of colour in the fruit and the rate of fermentation. In that experiment, although the green unripe fruit was never at any given moment as ripe absolutely as the well-coloured ripe fruit, nevertheless towards the end of the period over which the experiment lasted, it was actually in a much riper state than the coloured ripe fruit in the early stages of the period. But, in spite of that, in no instance was the rate of fermentation of its juice as slow as that of the juice of the other in its most rapid example. Other experiments with well-coloured and poorly-coloured fruits of several other varieties of apples have been made; and invariably the juice from the well-coloured fruit ferments more slowly than that from the poorly-coloured fruit of the same variety. Since the extent of the development of the colour depends upon the degree to which the fruit is exposed to the sun, it follows that direct sunlight seems to play an 
in portant part in influencing the chemical changes within the fruit, which affect the rate of fermentation of the juice.

From what has been stated above with regard to the part played by the assimilable nitrogenous substances in the juice in determining the rate of fermentation, it is to be expected that the differences in the rate at the various periods of ripening are due to variations in the quantities of these substances in the juice. Although this has not been directly proved by analysis, it is probably correct, since the addition of ammonium tartrate to juices from ripe fruit causes a decided increase in the rate of fermentation, thus showing that the comparatively slow rate is due, very considerably at least, to a deficiency of assimilable nitrogenous material.

Occasionally the mucilaginous substances in the juice are responsible indirectly for an appreciable effect on the rate of fermentation. They gradually undergo certain changes in the fermenting juice which frequently lead to the separation in insoluble form of various pectinous compounds. These are sometimes deposited gradually in small flocculent masses, but on other occasions, especially if the fruit has been at a certain stage of ripeness when milled, and if the acidity of the juice is below 2 per cent. malic acid, they are thrown out of solution by a clotting action. A thin jelly-like clot is formed throughout the liquid which slowly contracts in the manner of other clots, retaining all the solid matter originally suspended in the juice and also practically all the yeast cells. The liquor is in this way rendered as clear as if it had been filtered. The enclosure of the yeast cells within the contracting clot thus in a sense removes them from the juice; and fermentation is more or less checked until the clot disintegrates, which at times does not occur until many weeks later.

\section{The influence of the yeasts.}

Although it has been demonstrated that the rate of fermentation depends primarily upon the amount of nitrogenous yeast food present in the juice, the possibility of it being affected by the kinds of yeast taking an active part in the fermentation must be considered.

It is well known that different yeasts possess widely different powers of attenuation. Extreme cases could be instanced among the cider yeasts which have been examined at the Institute, and therefore the comparative influence of diverse forms upon the course of fermentation under practical conditions required to be determined. 


\section{The Rate of Fermentation of Ciders and Perries}

The behaviour of a large number of different yeasts in sterilised apple juice has been examined. It is not necessary here to refer in detail to the results, since beyond establishing the fact that there is a wide variation in the fermentative powers of many varieties, modified in extent according to the richness or scarcity of nitrogenous yeast food in the juice used, they have little direct bearing upon the problem under consideration.

It is the general custom in cider-making to allow the juice to ferment spontaneously, the usual result being that several different varieties of yeast simultaneously take an active part in the fermentation. As will be shown in a later paper the yeast flora of different ciders varies considerably; and it is therefore essential that there should be some knowledge as to the proper allowance to be made for such variations before a satisfactory conclusion regarding the factors which determine the rate of fermentation can be arrived at.

The examination of the yeast flora of ciders in a state of fermentation shows that there are as a rule one or more species present, which are capable of fermenting the cider to dryness, if the supply of nitrogenous yeast food and other conditions are suitable. The isolation and detailed examination of the different forms is, however, hardly necessary for this purpose, since, if ciders of comparatively high specific gravity in which the fermentation is very slow or has practically ceased are being dealt with, the addition of a small quantity of ammonium tartrate or some other nitrogenous substance which the yeast can assimilate at once leads to an increase in the rate of fermentation; and there is no cessation of fermentation, until the specific gravity is reduced to a low figure, thus proving that at least one of the ferments in the cider is capable of reducing it to dryness under suitable conditions. Examples of this effect have already been given above in Tables $\mathrm{C}$ and $\mathrm{D}$ in connexion with the consideration of the nitrogenous constituents of the juice.

The general results as a whole appear to indicate that the factor of the amount of nitrogenous yeast-food overshadows entirely the yeast factor, and that there are normally present sufficiently powerful ferments to produce the maximum rate which the nitrogenous contents and other conditions allow. Experiments with "dominant" fermentations by selected yeasts support this view. Several series of these have been carried on during the past four seasons. The results given in the two following Tables, $\mathrm{G}$ and $\mathrm{H}$, are typical of all, as far as they illustrate the point in question. In each series fresh juice direct from the press was 
used. The bulk required to fill the number of casks used was pumped into a large vessel, and there thoroughly mixed, after which each cask was filled with juice from this vessel and an active culture of one of the selected yeasts added. The quantity of yeast added to each cask was approximately the same, and was sufficient to dominate the character of the fermentation, this being essential since the juice was not sterilised, and therefore contained in a living state the organisms which would in the ordinary course of events set up spontaneous fermentation. In every series one cask was left uninfected, so that the "natural" and "dominant" fermentations could be compared.

TABLE G.

Juice obtained from a mixture of White Jersey and Cap of Liberty apples: pressed Nov. 21st, 1905 :

\begin{tabular}{|c|c|c|c|c|c|c|c|c|}
\hline \multirow{2}{*}{ Cask } & \multirow{2}{*}{ Selected yeast } & \multicolumn{7}{|c|}{ Specific gravity } \\
\hline & & Nov. 23 & Nov. 30 & Dec. 6 & Dec. 13 & Dec. 20 & Jan. 3 & Jan. 10 \\
\hline 1 & Yenst $\mathrm{C}$ & 1.052 & $1 \cdot 047$ & $1 \cdot 041$ & $1 \cdot 031$ & $1 \cdot 024$ & $1 \cdot 018$ & 1.011 \\
\hline 2 & D & 1.052 & 1.050 & $1 \cdot 044$ & $1 \cdot 033$ & $1 \cdot 026$ & $1 \cdot 016$ & $1 \cdot 011$ \\
\hline 3 & "E & $1 \cdot 052$ & $1 \cdot 050$ & $1 \cdot 045$ & $1 \cdot 034$ & $1 \cdot 027$ & $1 \cdot 017$ & 1.012 \\
\hline 4 & & $1 \cdot 054$ & $1 \cdot 051$ & $1 \cdot 044$ & $1 \cdot 033$ & $1 \cdot 026$ & $1 \cdot 020$ & $1 \cdot 013$ \\
\hline 5 & $\because \mathrm{G}$ & $1 \cdot 052$ & 1.050 & $1 \cdot 045$ & $1 \cdot 036$ & $1 \cdot 028$ & $1 \cdot 020$ & $1 \cdot 012$ \\
\hline 6 & $\begin{array}{l}\text { Natural } \\
\text { fermentation }\end{array}$ & $1 \cdot 053$ & $1 \cdot 050$ & $1 \cdot 016$ & $1 \cdot 037$ & $1 \cdot 031$ & $1 \cdot 022$ & $1 \cdot 016$ \\
\hline
\end{tabular}

Table $\mathrm{H}$.

Juice obtained from a mixture of Cap of Liberty, Yarlington Mill, Royal Wilding, and Strawberry Norman apples: pressed Nov. 26th, 1906 :

\begin{tabular}{|c|c|c|c|c|c|c|c|c|}
\hline \multirow{2}{*}{ Cask } & \multirow{2}{*}{ Selected yeast } & \multicolumn{7}{|c|}{ Specitic gravity } \\
\hline & & Nov. 26 & Dec. 1 & Dec. 3 & Dec. 4 & Dec. 5 & Dec. 7 & Dec. 28 \\
\hline $\begin{array}{l}1 \\
2 \\
3 \\
4 \\
5 \\
6 \\
7 \\
8 \\
9\end{array}$ & 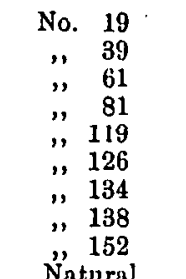 & $\begin{array}{l}1.052 \\
1.052 \\
1.052 \\
1.052 \\
1.052 \\
1.052 \\
1.052 \\
1.052 \\
1.052\end{array}$ & $\begin{array}{l}1.052 \\
1.052 \\
1.052 \\
1.052 \\
1.051 \\
1.052 \\
1.052 \\
1.052 \\
1.052\end{array}$ & $\begin{array}{l}1 \cdot 051 \\
1.052 \\
1.051 \\
1.051 \\
1.051 \\
1.051 \\
1.051 \\
1.051 \\
1.051\end{array}$ & $\begin{array}{l}1 \cdot 051 \\
1 \cdot 051 \\
1 \cdot 050 \\
1 \cdot 050 \\
1 \cdot 050 \\
1 \cdot 051 \\
1 \cdot 050 \\
1 \cdot 049 \\
1 \cdot 049\end{array}$ & $\begin{array}{l}1 \cdot 050 \\
1 \cdot 050 \\
1 \cdot 049 \\
1 \cdot 050 \\
1 \cdot 048 \\
1 \cdot 050 \\
1 \cdot 049 \\
1 \cdot 049 \\
1 \cdot 049\end{array}$ & $\begin{array}{l}1 \cdot 048 \\
1 \cdot 046 \\
1 \cdot 048 \\
1 \cdot 047 \\
1 \cdot 047 \\
1 \cdot 047 \\
1 \cdot 048 \\
1 \cdot 048 \\
1 \cdot 046\end{array}$ & $\begin{array}{l}1 \cdot 038 \\
1.033 \\
1.036 \\
1.035 \\
1.033 \\
1.035 \\
1.036 \\
1.036 \\
1.036\end{array}$ \\
\hline 10 & $\begin{array}{c}\text { Natural } \\
\text { fermentation }\end{array}$ & 1.052 & $1 \cdot 052$ & 1.052 & $1 \cdot 051$ & $1 \cdot 050$ & $1 \cdot 049$ & $1 \cdot 036$ \\
\hline
\end{tabular}




\section{The Rate of Fermentation of Ciders and Perries}

It will be seen from these tables that there was on the whole very little variation in the general course of fermentation of the individual ciders of the respective series: and what differences did occur may have been largely, if not entirely, due to causes other than the yeast influence. Such minor variations regularly occur in adjoining casks of the same cider fermented spontaneously: for which, as will be seen later, the casks themselves are probably largely responsible. It is also to be expected that uninfected ciders would ferment a little more slowly than infected juices, since the addition of an appreciable quantity of active yeast at the outset in the latter cases would naturally not be without some influence upon the course of fermentation, in its earlier stages at any rate. Even although the two ciders used did not differ so widely in their natural rate of fermentation as many fermented spontaneously, there was nevertheless a marked difference as a whole between the respective members of the two series as compared with the slight variations between individual members of the same series. The yeasts selected varied considerably in their powers of attenuation, No. 61 and $\mathrm{F}$ especially having comparatively low fermentative power, while No. 39 and $D$ are vigorous forms: but with neither of these extreme forms was the course of fermentation materially altered from the normal spontaneous type. Hence it is clear that at the most the variety of yeast used plays but a secondary part in determining the rate of fermentation; and, bearing in mind the results obtained with the yeasts of limited fermentative power, it seems probable that normally the rate is not far short of the maximum, which the composition of the juice as regards assimilable nitrogenous matter allows.

\section{The influence of aeration.}

As shown by Hansen (3) when a free supply of air is given to fermenting liquids an increased multiplication of the yeasts results: while if air is excluded, the rate of multiplication is lowered. The rate of fermentation is thereby affected, being quickened after the aeration of the fermenting liquid.

Cider and perry behave in the same way as other fermentable liquids in this respect, as was shown by the following experiment. A number of narrow-necked bottles were filled to the neck with freshly pressed juice from Spice pears, and placed in an incubator at $27^{\circ} \mathrm{C}$. Some were left uncorked and the remainder were corked, a vent tube being passed through the cork and opening under water to allow of the escape of the carbonic acid formed during fermentation. In the former a certain amount of air could come into contact with the juice at the 
exposed surface in the neck, although since the necks were narrow, the exposed surface was, relatively to the bulk of the liquid, exceedingly small. In the latter no air could come into contact with the juice. The daily records of the specific gravities were as under:

TABLE I.

\begin{tabular}{|c|c|c|}
\hline & Uncorked bottles & Corked bottles \\
\hline 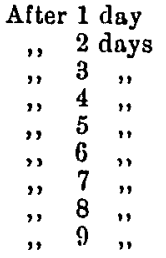 & $\begin{array}{l}1 \cdot 047 \\
1 \cdot 046 \\
1.040 \\
1.033 \\
1.026 \\
1.020 \\
1 \cdot 016 \\
1 \cdot 013 \\
1 \cdot 011\end{array}$ & $\begin{array}{l}1 \cdot 047 \\
1 \cdot 045 \\
1 \cdot 043 \\
1 \cdot 040 \\
1 \cdot 036 \\
1 \cdot 033 \\
1 \cdot 030 \\
1 \cdot 028 \\
1 \cdot 027\end{array}$ \\
\hline
\end{tabular}

The influence of the access of air was thus most marked in spite of the very limited exposed surface.

Similar experiments were carried out in 30 gall. casks in the cider house on the juice of mixed apples. Three casks, A, B and C, were filled to the bunghole with juice, which had previously been thoroughly mixed in a larger vessel. Over the bunghole of cask A a sheet of brown paper was pasted, and a pinhole made in it to allow of the escape of the gas given off by the fermenting liquor. No air could thus gain access to the cider. The bunghole in cask B was loosely plugged with a bung of sacking, so that not only could the carbonic acid gas escape easily, but also a limited quantity of air could find its way to the surface of the cider. Cask $\mathrm{C}$ was left unbunged, so that air could reach the surface of the cider exposed at the bunghole. The weekly records of the specific gravities were as under:

TABLE J.

\begin{tabular}{|c|c|c|c|c|}
\hline & & Cask A & Cask B & Cask C \\
\hline $\begin{array}{r}\text { When expe } \\
\text { After } \\
\text { " } \\
" \\
" \\
" \\
" \\
" \\
\text { " }\end{array}$ & $\begin{array}{l}\text { riment started } \\
1 \text { week } \\
2 \text { weeks } \\
3 \quad " \\
4 \quad " \\
5 \\
6 \quad " \\
7 \quad " \\
8 \quad " \\
9 \quad "\end{array}$ & $\begin{array}{l}1 \cdot 046 \\
1 \cdot 046 \\
1 \cdot 043 \\
1 \cdot 042 \\
1 \cdot 037 \\
1 \cdot 031 \\
1 \cdot 027 \\
1 \cdot 022 \\
1 \cdot 017 \\
1 \cdot 011\end{array}$ & $\begin{array}{l}1 \cdot 046 \\
1 \cdot 044 \\
1 \cdot 040 \\
1 \cdot 038 \\
1 \cdot 030 \\
1 \cdot 024 \\
1 \cdot 017 \\
1 \cdot 013 \\
1 \cdot 009 \\
1 \cdot 007\end{array}$ & $\begin{array}{l}1 \cdot 046 \\
1 \cdot 041 \\
1 \cdot 039 \\
1 \cdot 036 \\
1 \cdot 025 \\
1 \cdot 019 \\
1 \cdot 012 \\
1 \cdot 008 \\
1 \cdot 007 \\
1 \cdot 006\end{array}$ \\
\hline
\end{tabular}

Journ. of Agric. Sci. III 


\section{The Rate of Fermentation of Ciders and Perries}

In this series, again, although the final point reached was not very different, there was a considerable variation in the rates of fermentation, C fermenting most quickly, B next, and A slowest, the order thus corresponding with the amounts of air which could reach the respective juices.

A similar influence of air is noticeable in another connexion. It is the practice of certain makers to "keeve" the juice before placing it in the fermenting cask. In other words, the juice is pumped direct from the press to large open wooden vessels, the "keeves," in which it is allowed to remain as long as it will throw up solid matter in the "head" which is formed on its surface, the object of the process being to clear the juice quickly of its suspended solid matter. Other makers prefer to place the juice at once into the fermenting casks, which are ordinary casks standing on their sides, so that the froth and other matter thrown up in the "head" can work out at the bunghole. Several comparative trials of the two methods have been made at the Institute and it has been noticed on every occasion that, using the same kind of juice, fermentation starts sooner and proceeds for a time more rapidly in the "keeved" than in the "unkeeved" juice. For example, the juice from Oldfield pears, when keeved, dropped in specific gravity from 1.070 to 1.062 , while the same juice in cask, in the same period of time dropped only from 1.070 to 1.069. Similarly the keeved juice of Cummy Norman apples showed a drop in specific gravity from 1.058 to 1.039 as compared with a fall from 1.058 to 1.049 in the case of the unkeeved juice. Seeing that there is a large surface of juice exposed to the air in the "keeves," while there is only the very limited area of the bunghole exposed with the "unkeeved" juice, and that the other conditions are similar, it seems justifiable to conclude that the more rapid fermentation of the "keeved" juice is due to the greater exposure to air.

\section{The influence of temperature.}

That the temperature at which fermentations are conducted has an important influence upon the rate is well known. For every yeast capable of inducing fermentation there are maximum and minimum temperature limits above and below which respectively no fermentation occurs: and there is also an optimum temperature at which fermentation proceeds most rapidly. In the case of cider fermentations there seems to be no departure from the general custom in this respect; and 
there is no occasion therefore to go into detail on the subject. The following figures suffice to give a fair idea of the effect of temperature, and to illustrate that the comparative rates of fermentation of different ciders are much the same at a high as at a low temperature.

TABLE K.

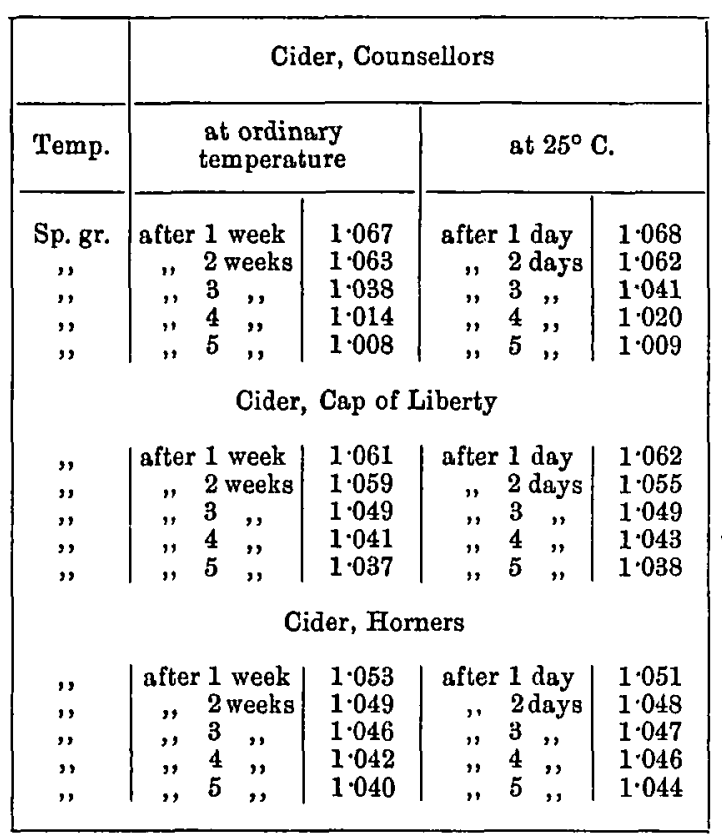

\section{Summary and Conclusions.}

The results of the work may be briefly summarised as follows :

(a) The rate of fermentation of ciders and perries made from different varieties of vintage fruit varies considerably.

(b) There is probably a relation between the rate of fermentation and the variety of fruit from which the cider or perry is made. Certain varieties, for instance, as a rule yield juices which ferment slowly, while others give juices which generally ferment at a rapid rate.

(c) The main factor in determining the rate of fermentation appears to be the nitrogenous matter present in the juice, which is assimilable by the yeast. The quantity of such substances present is generally insufficient for satisfactory nutrition of the yeast, and consequently the rate of fermentation is normally slower than would be the 
case if sufficient nitrogenous food were present to meet the full requirements of the yeast. The relative rates of fermentation of ciders and perries fermented under similar conditions are probably an index of the relative amounts of assimilable nitrogenous matter present.

(d) The state of ripeness of the fruit at the time of milling affects the rate of fermentation of the juice. During the course of ripening the rate becomes slower until a certain point is reached, which probably represents the period of perfect maturity of the fruit. Afterwards the rate increases in proportion as ripeness proceeds to decay. The degree of exposure of the fruit to direct sunlight also affects the rate of fermentation, the more exposed the fruit the slower the rate. In each case the result appears to be due to the quantity of assimilable nitrogenous matter in the juice being influenced.

(e) Direct influence on the rate of fermentation of the juice by any of the chemical constituents other than the nitrogenous substances has not been observed. If any have an influence, it is masked by other factors of greater importance. An indirect influence on the rate by the mucilaginous elements is occasionally met with, due to the formation of a clot which mechanically impedes the action of the organisms of fermentation.

( $f$ ) The rate of fermentation in practical cider-making does not appear to be materially affected by the fermentative powers of the kinds of yeast present in the juice. Normally there are present varieties which are capable of maintaining the fermentation at practically the maximum rate allowed by the nitrogenous constitution of the juice. "Dominant" fermentatiou with selected yeasts of bigh or low fermentative powers had comparatively little effect upon the rate.

(g) The aeration of the juice has a marked effect upon the rate of fermentation, the admission of air to the juice producing a decided increase in the rate.

(h) The temperature at which the fermentations are conducted affects the rate in the customary manner.

It is clear, therefore, that apart from the use of purely practical methods, e.g. filtration,- -which it is not intended to consider herea certain measure of control over the rate of fermentation of ciders and perries can be exercised by the cider maker, and that therefore the production of sweet and dry types of these beverages need not be more or less haphazard, as is commonly the case. By careful selection of the varieties of fruit used and by suitable blending of various types, combined with attention to the condition of ripeness of the fruit at the time of making, it should be possible to obtain a juice 
possessing the desired rate of fermentation, although some allowance for seasonal influences is necessary. These have not been considered above, as the work has not been extended over a sufficiently long period to allow of definite conclusions being drawn. At the same time it is fairly established that in some seasons the average rate of fermentation is much faster than in others. It would appear from the results as to the effect of direct sunlight as though the amount of sunshine during the period of ripening of the fruit upon the trees played an important part in seasonal influence. During the course of fermentation of the liquors the rate may be controlled to some extent by aeration and temperature.

Although the subject has been considered almost entirely from the point of view of the rate of fermentation, it should be mentioned that not only the rate but also the degree to which fermentation proceeds is involved. Although perbaps not invariably the case, as a rule fermentation can proceed to a further point in rapidly than in slowly fermenting juices. Accordingly no distinction has been made between them. In some cases the latter feature would more correctly express the facts than the former.

In conclusion I take this opportunity of expressing my indebtedness to $\mathrm{Mr}$ James Watts for his kindness in placing his factory at my disposal for experiments with selected yeasts; to the many cider makers and others, who have rendered considerable assistance in the direction of obtaining different varieties of vintage fruit required for the work; and to the various members of the staff of the Institute, who bave carried out the practical work in the cider house.

The National Froit and Cider Institute,

Long Ashton, Bristol.

\section{BIBLIOGRAPHY.}

1. W. B. Allwood. The Chemical Composition of Apples and Cider. U.S. Depart. of Agriculture, Bureau of Chemistry, Bulletin No. 88.

2. B. T. P. BARker. Reports on Cider-making, 1904-5, 5-6, 6-7, and 7-8. Annual Reports of the National Fruit and Cider Institute, 1905, 1906, 1907 and 1908. (Also published in the Bath and West and Southern Counties of England Society's Journal, 1905-6-7 and 8.)

3. E. C. Hansen. Compt. rend. de Carlsberg, 1879, Bd. 1.

4. Hogg and Graves Bull. The Herefordshire Pomona.

5. KuLIsch. Beiträge zur Kenntniss der chem. Zusammensetzung der Äpfel. Landw. Jahrb. 1892.

6. F. J. LLoYd. Report on Cider-Making. Board of Agriculture and Fisheries, 1903.

7. Troglde. Les meilleurs fruits de pressoir, 1895. 